\title{
Descriptive Study of 3D Imagination to Teach Children in Primary Schools: Planets in Outer Space (SUN, MOON, Our PLANET)
}

\author{
Satar Habib Mnaathr, Ahmed Dheyaa Basha* \\ Center for Instructional Technology and Multimedia (CITM), Universiti Sains Malaysia, Penang, 11800 \\ *Corresponding Author: ahmed2009shh@yahoo.com
}

Copyright (C) 2013 Horizon Research Publishing All rights reserved.

\begin{abstract}
This paper tries to support young children regarding their understanding about planets such as Sun, Moon and our planet by using technology, particularly through three-dimensional virtual environments, which whom are in primary school at the second stage, can have an early understanding about the shape of the Sun, Moon, and Earth, and the relationship among them, how the moon seems to change shape and how it occurs, phenomenon of day and night, through the use of vision of 3D holograms. 3D hologram vision system may be an effective tool for the teaching on various topics, like astronomy, which interpreted the relationships between objects in Aerospace. Presently, From other hand the Indiana state standards toward science education does not refer or suggest to the learning of this area and concepts for phenomenon of astronomy clearly, before fourth stage. So far, we expect our findings indicates that the students can learn from the previous these concepts in their learning lives with the implementation of these technologies. In addition the expect that these techniques could happen revolution and a quantum leap in education and raising the ability and cognition in children regarding in the understanding of scientific topics.
\end{abstract}

Keywords Virtual Reality (VR), 3D Holograms Vision, Outer Space, Children, Education, virtualized environments (VE)

\section{Introduction \& Background}

These phenomena were mentioned in Al -Quran with Soorat al Yassin in verses (36-40)."A token unto them is night. We strip it of the day, and lo! They are in darkness. (37) And the sun runneth on unto a resting-place for him. That is the measuring of the Mighty, the Wise. (38) And for the moon We have appointed mansions till she return like an old shrivelled palm-leaf. (39) It is not for the sun to overtake the moon, nor doth the night outstrip the day. They float each in an orbit". Proceeding from these, there are powerful arguments of developmentally occasion practice theories and maturations of the beliefs that young children cannot understand and increase more scientific notions, because of the limitation in their thinking abilities [1]. A few researchers maintain that immature children are not able to give an explanation about the astronomical phenomenon or ideas [2, 3].Children can so less scientifically correct explanation of the association between the moons, sun, and earth. From other hand, there is a strong impetus in order to increase the knowledge, awareness and learning of mathematics in elementary schools as described in state standards for mathematics, science and technology. As well, with the perspective of social constructivism in the curriculum, many researchers have noted for, the children are below the age preschool may be able to find out some of the scientific concepts [4]. With the cooperation, modeling and scaffolds. Software and images videos which mostly used particularly in support young children's understanding of the relationship between the earth, and, moon sun. To teach young children about the world and the things in the atmosphere, is that there is no possibility for children to fully understand that these are 3D Holograms Vision objects in the videos. Because they do not see the judiciously of things. Occasionally, as well, after teaching, students may acquire new misconceptions about the sun, moon and earth, like orbits, forms, and relationships among each one. May be due to of these limitations, Indiana State standards for learning of astronomy in the second stage (2010) refers to the scope of learning about astronomy in the second stage most be confined as rationalizing by the following cases on the website of learning standard. (Through these years, learning about objects in the sky should be fully monitored and qualitative, for children a far cry from willing to understand the quantities involved or the meaning out of the interpretations, First, students must get describing and noticing, what the sky seems like to them at various times. If they able, for instance, monitor the cases of the moon, and how it seems to change its shape, Although it 
is too early to label all the moon phases and a lot too soon to show them) $[5,6]$.

\section{A Glance about the Study}

By using technology, particularly through 3D virtualized environments, are these capabilities to help out young children in their awareness and understanding of the moon, sun and earth in terms of shapes .Three dimension technologies have already captured, the young student's attention in contexts of leisure such as video games and television. And we wonder what might present three dimensional visualization for young students in school education, especially in learning about the moon, sun, and earth, in science lessons for children. This study conducted in primary school in Iraq in Kl City, Malaysia

\section{Questions of Research}

With a multidisciplinary team consisting of the early kid instructor, computer scientist, Science instructor .We investigate whether or not; younger kids perceive the forms of outer space and relationship among them (earth, sun and moon), after they are supported by active exploration via $3 \mathrm{D}$ hologram vision system, in an urban school context. We particularly try to search these questions of research:

1. Can these techniques help kids to understand?

1.1 Phenomena of seasons why and how happen?

1.2 Why the appearance of the moon and its shape always changing?

1.3 Phenomena of day and night how it has happened?

1.3 Are our kids having ideas about the shapes of earth, sun and moon?

2. The kids in the second stage of elementary schools, are they able to enhance and increase their study results and awareness regarding their learning in school?

\section{Previous Study}

\subsection{Virtual reality systems of 3D holograms vision}

New developments in the field of information technology, empowerment capability computer graphics to create photos is more real, In contrast to conventional two dimension display devices. The 3D hologram device uses two images from the same place that is captured from little bit different corners or perspectives, by using specifically designed glasses, each eye picks up at various pictures from two overlapping pictures. Brain of human combines two pictures in one picture especially that permit us to understand in depth. Probably as a result of the high price of holograms vision has been used principally in technology areas within the past. Build a realistic three dimension hologram virtualized environments (VE) In the previous time was exclusively to the research centers for high visibility calculations, and automaker the design of the prototype, and defense-related firms for treatment and training [7]. On the other hand, the developments and advancements in computer technology significantly, which is utilized for representation the hologram images. By using the latest scientific advances in computers, so one can even create virtualized environments on the PC that can be displayed in 3D-compatible screens and projectors. Education is another rising space that would utilize this technology. Introduction of stereoscope into the education field has to date been tested as an efficient tool to enhance students' participation and conjointly increase their understanding of the topic. The computer game atmosphere has usually been used for e-learning applications. In two completely different studies, a web-enabled interactive system enforced, two subsystems of on-line virtual lab and on-line English education system toward natural learning environments $[8,9]$. As well as the virtualized environments were used for engineering education in another study. Use the augmented reality system for the Collaborative teaching Engineering for high school. And empirical tests have shown positive outcomes by using the virtualized environments in high school or university education $[10$, 11].

\subsection{Primary education and 3D imaging}

From the last previous studies, we noticed an insufficiency of studies specializing in the employment of virtualized environments, mainly utilizing 3D stereoscopy with younger youngsters in numerous academic contexts. A smaller number of studies exploring ways 3D models can support school learning for children in primary school. Some researcher found that six graders rated the utilization of a multi-representative construction model as ease of use, useful, and helpful in determination pure mathematics issues [12].Study in a European country that explored the utilization of the virtual surroundings within the context of a virtual interactive fantasy tale referred to as Magic house in thirteen grade school children's creative writing and motivation in skill learning has created positive results as expressed by teachers and students [13].The researchers also developed a marine 3D virtual museum of science education in primary schools of interest to strengthen the students' motivation to learn, especially because of the visual effects, and model-based learning game [14].Lastly, the goal of the study is to develop a 3D virtualized environment model named moon and sun System with 100 fourth graders, and Depending on the best students through their academic level and their grades in the previous, So that the student's level is the standard [15].

\subsection{Astronomy Education with Virtual Reality Systems (VRS)}

Three dimensional vision is a perfect resource to learn 
subjects as astronomy learning that shows the relationship among objects in three dimensions in outer space. There are many researchers assisted the impacts of virtual reality systems for astronomy learning in the class [16]. They carried out, the virtualized environment simulation of the solar system in order to improve Students' understanding in terms of concepts of astronomy. Additionally, empirical studies have shown that held by the primary school, secondary school and undergraduate students; improve learning outcomes and participants expressed favorable opinions on the suggested regulations [17]. Moreover in these studies with the virtual environment, students' perceptions of the outer space associated with planets. Also other astronomical objects shown to them have a smaller number of wrong concepts after instructions and mentality styles; seem more accuracy in scientific aspects [18]. We hope, similar outcome will be seen from our research using this technology in the primary stage.

\section{Methodologies}

\subsection{Model System Configuration}

Our group in this study is on the right way to develop software for visualizing 3D model and particular spectacles to surveillance the Planets in outer space like the moon, sun and our planet (the earth) in an environment of VR in Classes. To accomplish this system we are adopting some programs and tools such as Java programming, object-oriented graphics rendering engine (OGRE) and SketchUp for modeling the objects of planetary with many multimedia means .So it was constructed as a model system that displays a solar system. The users can move in astronomical Photo in the stereoscopic seeing by using altos tools and many techniques such as 2 monitors, and $120 \mathrm{~Hz}$ three D Samsung Sync Master LCD Monitor, NVIDIA GeForce 3D view Kit counting wireless active cover up or shutter spectacles and infrared emitter USB-based synchronize. We work to promote the realistic of the virtual environment also to develop and enhance the mechanisms of the Communication and interaction axiom for students in early childhood education. Systems will completion of the project photo by using a short throw DLP the viewer that Allows students to understand and experience the stereoscopic $3 \mathrm{D}$ images using cheap 3D spectacles of polarized.

\subsection{The Application}

We will work together with second stage schoolroom academics to make the science classes so as to implement three dimensions technology. The timeline of the analytical study is just about 2-3 weeks of instruction in appointing science lessons. Students are shown an enormous screen as they're additionally given three dimensions spectacles to watch the planets such as the Moon, Sun, and Earth, as well as their interactions with each other Students are going to be ready to explore the software package and manipulate objects within the sky in little teams. Therefore, they'll either be within the position of the audience, or participators. The scholars can still observe, manipulate, and find out about the interactions and therefore the relationships between the Sun, Earth, and Moon with the guidance of the teacher.

\section{Evaluations}

Pre and post interviews with students are conducted as a way of qualitatively measuring and detecting their information regarding the interactions and therefore the relationships among the three planets, and exploring their attitudes and motivation towards science learning. Students' college work, specifically writing and drawing items are collected, coded, and quantified to assess the impact of the intervention. A suitable instrument to measure students' motivation and attitude in respect of science learning is a questionnaire, to reach and achieve this goal.

\section{Conclusions}

In this study and analysis we have a tendency to propose that it would be doable for younger youngsters to find out regarding the Sun, Moon, and Earth, notably their shapes, the connection among them, like night and day, Moon's ever-changing look and seasons with the assistance of three dimensions (3D) visual image. Therefore, this analysis hypothesizes that second stage or graders will have associate understanding concerning the form of the Moon, Sun, and Earth, as well day and night happen, and the way the Moon changes its shapes earlier in their study live if they're ready to imagine their movement in an exceedingly 3D VE. The choice of emphasize on an urban low attainment school aligns with our goal in research providing children from disbenefits communities with each opportunity to use new Imagination technologies in their education. This point of view will also help us customize and determine whether supporting children's school learning with these new technologies also enhancing their motivation and self efficiency as new successful learners. In our outcomes point to that learners can learn these concepts earlier in their educational lives easily with the applications of such technologies, we think these technologies could reconstruction ideas when these concepts could be learn children and greater broaden our thinking about children's cognitive and upgrade their knowledge and capacities in understanding scientific concepts.

\section{Acknowledgements}

We are very grateful and highly appreciate for Iraqi primary school in KL Malaysia to help us in our research as well as our center (CITM) -USM- Malaysia. 


\section{REFERENCES}

[1] P. M. Fernbach and S. A. Sloman, "Causal learning with local computations," Journal of experimental psychology: Learning, memory, and cognition, vol. 35, p. 678, 2009.

[2] V. Frède, G. Nobes, S. Frappart, G. Panagiotaki, B. Troadec, and A. Martin, "The acquisition of scientific knowledge: the influence of methods of questioning and analysis on the interpretation of children's conceptions of the earth," Infant and child development, vol. 20, pp. 432-448, 2011.

[3] I. F. Pollack, R. L. Hamilton, R. W. Sobol, M. N. Nikiforova, M. A. Lyons-Weiler, W. A. LaFramboise, P. C. Burger, D. J. Brat, M. K. Rosenblum, and E. J. Holmes, "IDH1 mutations are common in malignant gliomas arising in adolescents: a report from the Children's Oncology Group," Child's Nervous System, vol. 27, pp. 87-94, 2011.

[4] E. Kikas, T. Hannust, and H. Kanter, "The influence of experimental teaching on 5-and 7-year old children's concepts of the Earth and gravity," Journal of Baltic Science Education, vol. 1, 2012.

[5] M. Saçkes, L. M. Flevares, and K. C. Trundle, "Four-to six-year-old children's conceptions of the mechanism of rainfall," Early Childhood Research Quarterly, vol. 25, pp. 536-546, 2010.

[6] S. Özsoy, "Is the earth flat or round? Primary school children's understandings of the planet earth: The case of Turkish children," International Electronic Journal of Elementary Education, 4 (2), pp. 407-415, 2012.

[7] K. Burger, "How does early childhood care and education affect cognitive development? An international review of the effects of early interventions for children from different social backgrounds," Early Childhood Research Quarterly, vol. 25, pp. 140-165, 2010.

[8] D. Mellet-d'Huart, "Virtual Reality for Training and Lifelong Learning," Themes in Science and Technology Education, vol. 2, pp. pp. 185-224, 2012.

[9] L. A. Annetta, J. Minogue, S. Y. Holmes, and M.-T. Cheng, "Investigating the impact of video games on high school students' engagement and learning about genetics," Computers \& Education, vol. 53, pp. 74-85, 2009.

[10] C.-Y. Chen, B.-Y. Shih, and S.-H. Yu, "Disaster prevention and reduction for exploring teachers' technology acceptance using a virtual reality system and partial least squares techniques," Natural hazards, vol. 62, pp. 1217-1231, 2012.

[11] L. Snider, A. Majnemer, and V. Darsaklis, "Virtual reality as a therapeutic modality for children with cerebral palsy," Developmental Neurorehabilitation, vol. 13, pp. 120-128, 2010.

[12] M. Tsuei, "Using synchronous peer tutoring system to promote elementary students' learning in mathematics," Computers \& Education, vol. 58, pp. 1171-1182, 2012.

[13] A. Meluso, M. Zheng, H. A. Spires, and J. Lester, "Enhancing 5th graders' science content knowledge and self-efficacy through game-based learning," Computers \& Education, vol. 59, pp. 497-504, 2012.

[14] S. U. Baig and A. A. Rahman, "Generalization and Visualization of 3D Building Models in CityGML," in Progress and New Trends in 3D Geoinformation Sciences, ed: Springer, 2013, pp. 63-77.

[15] A. Srivastava and J. Ramadas, "Analogy and Gesture for Mental Visualization of DNA Structure," in Multiple Representations in Biological Education, ed: Springer, 2013, pp. 311-329.

[16] L. Annetta, J. Mangrum, S. Holmes, K. Collazo, and M. T. Cheng, "Bridging realty to virtual reality: investigating gender effect and student engagement on learning through video game play in an elementary school classroom," International Journal of Science Education, vol. 31, pp. 1091-1113, 2009.

[17] T. A. Mikropoulos and A. Natsis, "Educational virtual environments: A ten-year review of empirical research (1999-2009)," Computers \& Education, vol. 56, pp. 769-780, 2011.

[18] Z. Isik-Ercan, B. Kim, and J. Nowak, "Can 3D Visualization Assist in Young Children's Understanding of Sun-Earth-Moon System?," International Journal of Knowledge Society Research (IJKSR), vol. 3, pp. 12-21, 2012. 